\title{
Scarpia, laboratorio de arte a orillas del Guadalquivir
}

Desde su nacimiento en 2002, Scarpia se plantea como unas jornadas de intervención artística en los espacios naturales y urbanos del municipio de El Carpio, una localidad de tan sólo 4500 habitantes a 30 km de Córdoba capital. A lo largo de las distintas ediciones, se han producido y realizado más de 120 intervenciones en el paisaje de El Carpio y se han celebrado un centenar de conferencias de la mano de arquitectos, paisajistas, artistas e historiadores. Además, Scarpia ha contado con la presencia de artistas como Daniel Canogar, Rogelio López Cuenca o Mateo Maté, entre otros, que han impartido distintos talleres de creación.

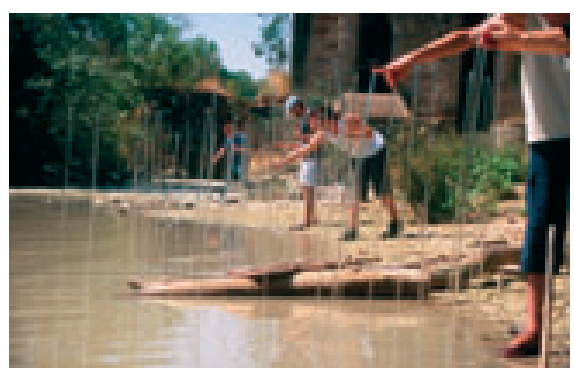

El Canto de Jaurosky, de Manuel Muñoz Foto: Manuel Muñoz

De esta forma Scarpia se ha ido consolidando como un laboratorio de ideas y proyectos de creación sumamente dinámico, en lo que a planteamientos de arte del paisaje se refiere.

El Carpio presenta multitud de registros paisajísticos: el casco urbano vivo, rico y diverso -dominado por la Torre del Homenaje del castillo de Garci-Méndez de Sotomayor-se funde en sus inmediaciones con la campiña y con el Guadalquivir, que baña sus tierras. Esto hace que las producciones específicas de arte

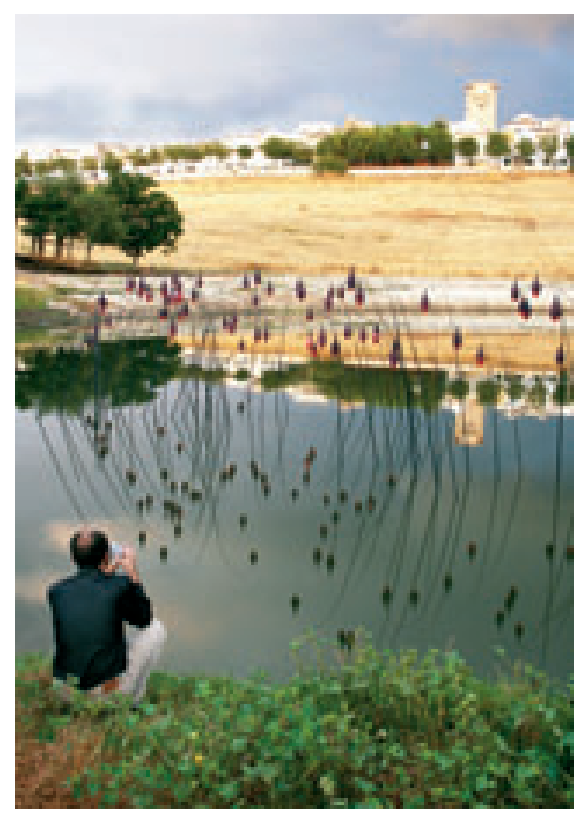

Todos los caminos llevan aroma, de Monique Bastiaans. Foto: Marianna Papapietro contemporáneo, en este contexto, incorporen un interés añadido al rico patrimonio de esta localidad.

Varias intervenciones artísticas, a lo largo de sus ocho ediciones, han mirado al río y han dejado tras de si muchos planteamientos acerca del Guadalquivir, sus valores patrimoniales y sociales, haciendo reflexiones con una visión critica, poética y experimental a través de instalaciones, fotografías o performances de artistas como Ángel Garcia Roldán, Manuel Muñoz, Antonio R. Montesinos, Monique Bastiaans, Miguel Gómez Losada o Sara Moyano.

La vitalidad de la naturaleza, la problemática del medio ambiente, la música o la opera, han sido los discursos que han tocado algunas de las actuaciones realizadas, como la de Martín Solis Moreno, en la primera edición, que realizó con piedras una gran Arroba (@), parafraseando la creación del universo de la Spiral Jetty del artista americano Robert Smithson. En este caso se evoca el nuevo mundo virtual que nos ha tocado vivir jugando directamente con un icono del Land Art.

En el año 2004 el fotógrafo Manuel Muñoz realizó una intervención que se titulaba El Canto de Jauros$k y$, livianos juncos de cristal cuya escenografía eran las grúas, los molino del río. La fragilidad del cristal creaba tal tensión con el agua y el barro del río que parecia que de un momento a otro se rompiese tan delicado material, el agua y el viento susurraban por los agujeros de estos juncos de cristal que se iban hundiendo en el río como si se fundieran con el verde del Guadalquivir, produciendo una atmósfera irreal.

Sara Moyano realizó, en el 2006, Frágil, una balsa hecha de fragmentos de botellas de agua, instalada

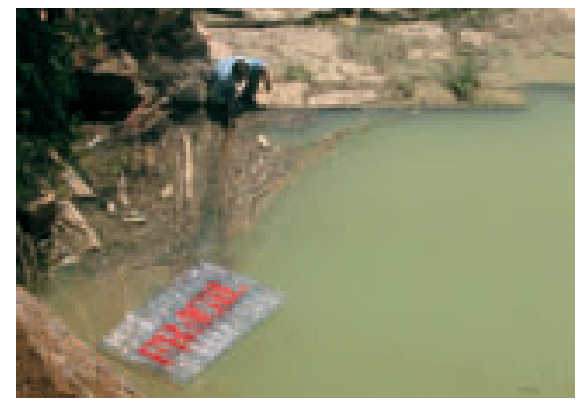

Frágil, de Sara Moyano. Foto: Miguel Ángel Moreno Carretero

durante 10 dias en un lugar donde las corrientes del río acumulan residuos. La obra parecia hecha por el propio río pidiendo auxilio.

Le Petit Tour fue un proyecto realizado por Antonio R. Montesinos para la última edición de Scarpia. En él se reflexionaba en torno a la actividad turística de la ciudad de El Carpio, estableciendo una relación entre el paisajismo como género artístico y el senderismo como fenómeno de "práctica del paisaje". La intervención en el espacio se alejaba de la idea de monumento, ya que no se colocaba ningún objeto grandioso en él. En lugar de eso se daba protagonismo al propio espacio natural intervenido, encontrando lo grandioso en el propio paisaje por medio de su exploración y marcado. El proyecto sigue en http://www.armontesinos.net/lepetittour/.

Miguel Ángel Moreno Carretero Scarpia

Maria Anna Papapietro

Centro de Documentación y Estudios del IAPH

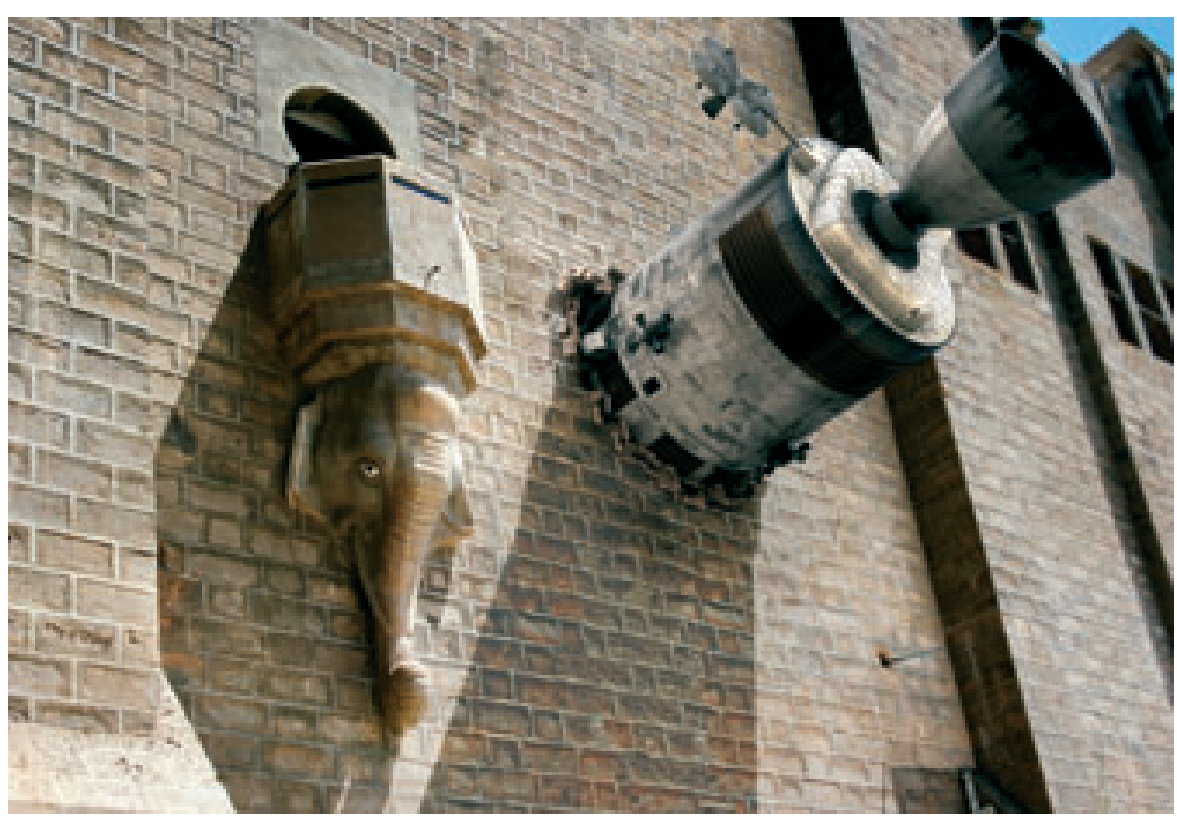

Fotomontaje de Manolo Bautista sobre la presa de El Carpio 